8 Research Square

\title{
Learning from the pandemic, building international increased cooperation for the future
} \author{
401X \\ John Middleton \\ ASPHER
}

Henrique Lopes ( $\square$ henrique.lopes@ucp.pt)

Universidade Católica Portuguesa: Universidade Catolica Portuguesa https://orcid.org/0000-0002-7586-

\section{Research}

Keywords: Pandemic, framework, crisis management levels, strategic management, tactical management, internationalization

Posted Date: April 26th, 2021

DOl: https://doi.org/10.21203/rs.3.rs-452329/v1

License: (a) (i) This work is licensed under a Creative Commons Attribution 4.0 International License. Read Full License 


\section{Abstract \\ Objective}

The COVID-19 pandemic highlighted a fragile preparation by countries and regions for epidemic events, exposing exacerbated nationalisms in pandemic mitigation and control actions. Both conditions decisively compromise the effectiveness and efficiency of pandemic control capacity. It is important to develop frameworks that help overcome frailties in response to epidemics.

\section{Methods}

Thematic literature review and discussions with multiple national and international entities. The discussions were not specific to the article, hence were not considered as formal information collection. Based on this information, an attempt was made to build a tool for responding to the identified problems.

\section{Results}

Proposal of the 2PF tool.

\section{Conclusion}

The proposed 2PF tool is aligned with the Sendai Framework and proposals from international bodies, such as HERA, among others. It aims to be a framework for operationalizing these agreements, at least in part of its dimensions. The general idea is that pandemic preparedness cannot fail or to all other disaster risks and similar recognized by the UN. The response to pandemics must be based essentially on international action and closer collaboration between countries and regions.

\section{Introduction}

The current pandemic is devastating countries, especially those in the West, in multiple ways: directly regarding more vulnerable and older populations (1); indirectly in almost the entire population via economic and social means (2). Only extremely wealthy population fringes appear to be more immune to the pandemic (3).

On the contrary, Asian and African countries show much better results, thus opposing the expectations that countries with better health systems would be better prepared to deal with a pandemic event. Examples are easy to find (4) by analyzing total deaths and COVID-19 cases per one million inhabitants (hereby presented as Deaths|Total COVID-19 Cases pMhab.), as per the 1st April 2021 in Asia (Taiwan: 0.4|43 pMhab.; Vietnam: 0.4|27 per Mhab.; Mongolia: 2|2.546 pMhab.; etc.), in Africa (Eritrea: 3|917 pMhab.; Benin: 7|575 pMhab.; Chad: $10 \mid 270$ per Mhab.; etc.) and others. The argument that this low incidence and mortality is due exclusively to different demographic structures and great cultural differences that lead to less transmissibility 
of the disease can demonstrate (4) that Westernized countries that have undertaken determined Public Health policies have also been successful: New Zealand (5|499 pMhab.), Singapore (5|10.261 pMhab.), Cuba (37|6.648 pMhab.), Australia (35|1.139 pMhab.).

The situation was close to a catastrophe in Western countries (4), with some of the most affected nations when assessing the incidence and mortality of COVID-19 being identified as follows: Belgium (1.975|75.413 per Mhab.), Czech Republic (2.464|142.891 per Mhab.), the USA (1.700|93.733 per Mhab.), the UK (1.859|63.767 per Mhab.) and others. The same conclusion can be reached if measured in economic and social impact (5). In developed countries (6), an older population and a high diagnostic capacity have contributed significantly to the observed positions shown above. However, there have also been systematic failures in managing to activate the most appropriate Public Health policies. Western countries have failed mainly by arrogance in its assumption that national health systems functioning, as usual, would be sufficient to deal with the pandemic.

Countries in the West insisted on not taking the appropriate SARS-CoV benchmark preparation measures taken by the countries that dealt with the 2003 SARS outbreak and swiftly putting them into practice. We point out measures such as the provision of field hospitals ready to be deployed where necessary, adequately equipped to deal with respiratory diseases, with personnel from regions not yet affected; those that were in some way related to mass communication, and that face the corporate status quo, traditions, among other reasons, as a pandemic requires a collective behavioural act. There was also a refusal (in facto) to learn from countries peripheral to the Western nations by analyzing what they were doing right in this pandemic (Uruguay, Ruanda, Vietnam, among others) and understanding how good results were obtained. The learning transpositions originated from outside the European and American continents are very scarce. There was not even the ability to learn from the experience of those affected early in the pandemic (7), as it was, for example, overly demonstrated with all initial resistance to the use of masks.

This posture resulted in pandemic waves of increasing intensity, despite a large part of the clinical resources having been diverted to COVID-19 (8). This action required the postponement of countless medical intervention for non-COVID conditions (9), which will undoubtedly result in worse future clinical conditions, more deaths, among other situations. Oncology, cardiology (10) and gastroenterology (11) will be heavily affected in the pandemic's aftermath. National Authorities were grossly unprepared for the pandemic situation (4). However, it should be noted that the alert for this pandemic dates from October 2007 (12).

\section{How to explain the failure of the most sophisticated health systems on the planet?}

Undoubtedly health systems that have provided excellent responses in thousands of diverse clinical dimensions over almost a century have not suddenly become incapable or less intelligent. There was no shortage of economic, human or technological resources to fight the pandemic in those countries. On the contrary, there has been the greatest focus on health response capacity ever assembled to combat the pandemic. Furthermore, the greatest scientific advances were also verified, namely in understanding the virus and generating scientifically innovative responses, such as the enormous quantity of vaccines developed in 
Western countries in record time (13). For these reasons, there was no failure of the scientific community in response to COVID-19.

It should also be noted that collectively, as Societies, Western countries being the most affected by the pandemic were also the ones that made the most significant economic and financial efforts during this period: successive lockdowns, support to companies and workers of different social nature to compensate the lockdowns. That effort has so far represented trillions of Euros or USD (14). One of the greatest lessons that can be learned from this pandemic is the profound link between Health and the Economy (15).

All these efforts did not work positively. At most, it mitigated the impact of the pandemic. Despite this mitigation, unemployment has increased (16) and bank credit advances (17) allows anticipating the surge of a vast economic crisis after the pandemic. In a general reading, the Sustainable Development Goals will either not be achieved or partially achieved (18).

This pandemic was generally approached as if it were just one more epidemic, as happens annually with flu (19). At first, the response pattern only intensified. In essence, at a national level, the conceptual tool for responding to the pandemic was the same as that of the current assistance to most illness situations: issuing of Norms and Procedures, training of Health professionals, particularly, Hospital staff in the methods and techniques that are expected to best respond to the situation, hospital partial allocation exclusively to the new threat.

Since the first moments of the pandemic, the reality has been that employed efforts were insufficient. For example, health personnel lacked masks and other basic Protective Personal Equipment (PPE), even in the largest financial capitals (20). There were almost no critical material reserves in hospitals and suppliers, as the Just in Time (JIT) supply chain management systems philosophy and other management efficiency tools had reduced hospital stocks to the essential and immediate. Furthermore, the search for financial efficiencies in the supply chain meant all essential production was from Asia (21), placing Western countries in total dependence on the producing countries' goodwill.

Field hospitals ready to use and equipped with teams of professionals previously assigned, as seen in China (22), did not exist in Western countries. Only adapted spaces and in last resort through the sacrifice of already affected Hospital teams (23), or patients' transfers from the most affected areas to others less affected (24). However, this solution was only occasionally used and without expression on the global pandemic values.

The preparation of resources to face a biological threat was essentially absent, with honourable exceptions being registered (25). Knowledge management was almost equally fragile. Contrary to what has been happening for decades in seismology, volcanology, flood control and more recently, with the European Forest Fire Information System (EFFIS) tool in the surveillance and control of large-scale forest fires (26), the area of surveillance and response to biological risk had little to offer except for the WHO Flu preparation Programs $(27-29)$.

We must be restrained, for ethical reasons, to the most immediate criticisms of the failure of results that add to morbidity, mortality, and economy. There is veiled and systematic criticism towards Health Systems, both 
national (30) and international (31). With the available resources, small miracles were performed every day. Generally, health systems worked well, with improvements and adaptation being necessary as it has been happening for decades (32). That is why we do not add up to these criticisms and, on the contrary, defend that the existing structures of the WHO, UNISDR, ECDC, CDC and FEMA (national level) should be supported and reinforced in their action.

In summary, it can be stated that the response of the European and American countries was:

1. Passive, indecisive and slow.

2. Bureaucratic-Normative.

3. Without conceptual preparation for surveillance, preparation, or coordination of actions on the field.

4. Without strategic reserves of PPE material nor significant hospital reserves (facilities and capacity).

5. Lacking pandemic response tools at the macro, meso or micro level.

6. Nationalist centred, paying little attention to WHO or other international authorities.

7. Low knowledge management and knowledge transference near the countries that know more about the field: SARS-CoV like virus and infectious diseases.

In our reading, much of this result is due to consecutive years of disinvestment in Health in Western countries, especially in the last decade and because Public Health is always the poor branch of Health, the one in which little is invested, where little space is given to the preparation of people and logistics (33). This cycle must be reversed, placing Public Health as a strategic tool for the Nations, investing at all levels in which it operates, strengthening the entities where it works, eventually creating ways to improve the interfaces between levels and between countries. Therefore, we propose a Framework for dealing in an integrated manner with future epidemics or pandemics.

\section{Methods}

Looking to the future: the need for a conceptual Framework for Biological Risk Prevention and Epidemic Impact Mitigation, the 2PF (Pandemic Preparation Framework)

Pandemics and epidemics will undoubtedly return in the current century. All the conditions for increased circulation of individuals, goods, climate change, contact with wildlife and devastation of ecosystems previously untouched by humans are currently gathered and will worsen in the predictable horizon. The latter conditions are estimated to generate around $60-70 \%$ of new diseases and epidemics (34). Therefore, we must prepare so that the Public Health catastrophe of COVID-19 will not be repeated.

Much can be done without relevant effort if the lessons of COVID-19 and the accumulated experience of decades in the surveillance and mitigation of effects caused by natural risks are considered. Therefore, we propose the creation of a Framework for Approaching Biological Risk with Pandemic Danger - the Pandemic Preparation Framework (2PF).

With the 2PF, we propose a way of dealing with future epidemics/pandemics that can at least partially address the difficulties and problems of the seven weaknesses in Western countries health response during the COVID-19 crisis, as summarized above. 
Four Principles support 2PF (Fig. 1):

1. Pandemics and major epidemics are overcome in the Prevention phase.

2. When it is no longer possible to maintain either situation with very high certainty in the Preventive phase, there must be a Planning and Preparation phase for concrete risk.

3. Proactive response to the pandemic when it is already installed on the field.

4. The identification, prevention, planning of preparation and combating a Pandemic or major Epidemic can only be successful through total International Cooperation.

The strategic idea is that the coordination of the response to an epidemic/pandemic must be essentially achieved at a supranational level, through adequate prior preparation and based on knowledge management. The need for this paradigm shift was recently addressed at the European Union level, with the regulation entity proposal entitled "European Health Emergency Preparedness and Response Authority" (HERA) (35). However, with emerging diseases having the potential of becoming a global threat, a more global approach was reinforced by the signature of a Global Pandemic Preparedness Treaty by 24 world leaders and the WHO (36).

During the Twentieth century, the world has progressed from national to supranational entities whenever the Common Good is to the parties' advantage, of which the ultimate example will be the United Nations (UN). Countries have also learned that major crises are faced by cooperation and have created mechanisms for that purpose within supranational organizations. In an increasingly globalized world where everything tends to occur almost simultaneously, only international solutions based on cooperation will be able to respond to major issues since what affects a country can quickly become a global threat. Therefore, it is in the direct interest of all nations to participate in the elimination or mitigation of a risk in any country in the world. For example, since 2005, with the signing of the UN Hyogo Framework (37) for response actions to disasters, and later with the Sendai Framework for Disaster Risk Reduction (38), global targets were defined towards reducing disaster consequences such as: mortality, affected people, economic loss in GDP, infrastructural damage and service disruption, national/local risk reduction strategies, international cooperation, availability and access to multi-hazard warning systems.

The COVID-19 pandemic has shown beyond a reasonable doubt that the capacity to control a pandemic is something that goes beyond the national dimension, as declared by many politicians (39) and scientists (32). Only through the highest international cooperation is it possible to find appropriate solutions, supply equipment volumes at an adequate time and acceptable prices, with universal standards and applicability, and exchange experiences to debug national procedures.

International cooperation in a pandemic state has immense scope for progression in all fields (40). The degrading spectacle of government officials re-directing clinical equipment at airports should not be acceptable (41). Many national strategies have sought only to concentrate the maximum level of resources with those who can afford them. For example, in the case of worldwide vaccine distribution there is the need of international agreement on its optimal and adequate allocation instead of being focused in profits (42) and realpolitik (43). International authority is needed to ensure resources go to areas where they can be globally most useful and effective in combating the pandemic (44). 
The absolute need for knowledge management was verified, proving to be the central element for an adequate fight against the pandemic. This element can only be appropriately developed in a wide-ranging, fully internationalized way and with the greatest transparency.

Finally, it should not happen again that the strengthening of local response capacities through international means is minimal and appears as an insufficiency of the local political response. In the COVID-19 pandemic, the international reinforcements that existed were vestigial $(44,45)$ concerning the means deployed in each country and always with difficulties articulating with the local structures that led to situations in which even the smallest help made available was not used: language, local procedures and other complexities (45). Only the creation of automatisms can change this framework for the integration of Health Services.

The tactical-operational idea is that national/local actions must be part of an articulated whole composed of three dimensions: Prevention, Planning and Preparedness, Proactive response to the pandemic. This means that there must also be a high level of international operational cooperation, presenting the great challenge of requiring mutual knowledge and preparation work.

Things as simple as consolidating new positive cases or the lethality of a disease among countries can, in practice, be an impossibility when each country works in its own way. Consistency in case definitions and ascertainment is needed, for example, to secure cross border intelligence and enable accurate inter-country comparisons.

With the ongoing COVID-19 pandemic threat, it must not be forgotten that there are other biological threats still emerging, as seen recently with avian influenza (H5N8) in Russia (46) and the African Swine Fever in Poland (47). These examples and other situations have been mainly dealt with by the national structures in which the threat emerges, a context that, despite being local, may reach the planetary scale if not controlled and for which there is little to no international response. It is important to note that every nation has a responsibility in preventing and reducing disaster risk, surpassing the national-level interventions, including cooperation with other nations and regions (48). Following this approach, reacting promptly to a threat requires having previously allocated, trained, certified resources in sufficient quantity and the capacity to travel to another part of the planet, if accepted and allowed, to immediately integrate the national structures in an environment of full informational transparency.

Pandemic preparedness investment is beyond almost all countries' capabilities, which greatly reinforces the need to be thought out globally. The WHO is the organization naturally dedicated to having these global competencies. However, to be able to address this issue, it is essential to have a great reinforcement of human, financial and technological resources. In Western countries, the main Cooperation Bodies are the WHO, ECDC and CDC/FEMA, which also need to have their skills and resources strengthened to be able to deal proactively and appropriately with the epidemic/pandemic risk.

\section{Results And Discussion}

\section{A proposal to create the new operational mesostructure}


In addition to strengthening international bodies whose nature leads them to macro health policies approaches (WHO, ECDC, CDC/FEMA, among others), we propose the creation of a new entity, on a continental scale, with national representation in each country for connection to health systems. Therefore, it has a different nature and is complementary to the existing bodies with a vocation for field action in biological risk situations and the capacity to strengthen local structures designed to deal with disruptive health situations such as pandemic contexts. Considering the pandemic/epidemic generating factors strongly associated to contact with wildlife, this entity should also integrate and consolidate veterinary and agricultural knowledge within the Public Health dimension.

It should comprise and work similarly with what already exists in the civil protection for natural risks, where the teams are previously trained, identified and whose respective material and logistics are part of international cooperation plans, thus providing a modular capacity for integrated work.

It is possible to capacitate this entity for action regarding other health threats besides pandemics (48): largescale earthquakes, large industrial accidents as happened at Bhopal (49), or others that by nature exceed the country's response capacity in the healthcare action sphere. Similarly to the other risks already covered with this type of response, aid must not be read as a weakness in a given country but as a collective response to a threat that has occurred in a given space.

Biohazard plans must be directly linked to the preparation for action on the field. The entity must know the concrete field where the threat occurs, the existing and missing resources, and the hierarchy of supply priorities for a given risk in a given location when the event occurs. The entity must also have the first materials available to support risk mitigation. To properly perform its functions, the entity needs two fundamental competencies: knowledge management and emergency logistics (heavy materials as modular hospitals fully equipped with devices, personnel and light materials as PPE/medicines stocks).

In addition to being guided by the latest scientific evidence and WHO advising, it must have the capacity to analyze risk and advise policymakers before substantial evidence is gathered, whenever the need to act is more pressing than the evidence available at that time in what we could name by health crisis management. The difficulty of many Governments and Authorities in providing clear directives was evident in the absence of scientific evidence, which resulted in numerous delays (50). Countries that opted for the proposed forms of decision that were sometimes more crisis management than scientific ended up having better results than Western countries, as happened in South Korea and New Zealand.

\section{PF in action}

\section{Knowledge management}

The international body should have Knowledge Management competencies for the proactive monitoring of potential risks, anticipating as far as possible which biological agents have pandemic capacity while designing strategic and tactical response plans that help containing the threat in early stages. The entity should promote training to national and international agents to interconnect, in case of a biological threat, and field exercises to test the respective systems' weaknesses and provide them with tactical tools. 
We propose that the entity works on an association between Risk and Probability (Table 1). This will result in each continental zone having a Biohazard Letter that will allow Governments to prepare conveniently, or at least have that opportunity.

\section{Table 1 - Table of Risk identification and action priority rankings (scale from 1 to 5)}

\begin{tabular}{|llll|}
\hline Risk $^{\text {Probability }}$ & High & Medium & Low \\
\hline High & 1 & 2 & 3 \\
\hline Medium & 2 & 3 & 4 \\
\hline Low & 3 & 4 & 5 \\
\hline
\end{tabular}

Note: The intersection of each risk level is identified as a scale from 1 to 5 , in which 1 represents a primary priority and 5 represents the latter priority.

The creation of data quality assurance tools about the threat must also encompass knowledge management work, such as ensuring easy consolidation of data and semantic sharing.

\section{Logistics}

Another competence of this supranational entity is to have a minimum reserve of protective materials (Field Hospitals, critical medical devices, PPE and other equipment) that enable the first action against a pandemic, at least in the early days, until industrial supply chains are adapted to the new reality. Under this view, time is critical for prompt action and efficient crisis management. All threats contained in a first moment will be much easier to deal with than after spreading to large areas, as happened with COVID-19.

The set of procedures deployed in countries should also be worked on towards the greatest harmony possible, at least at a level that allows for the reinforcement teams not to spend several days studying local procedures before starting to work (51). It must also be ensured that at least critical medical devices can interconnect.

Furthermore, there is a need to respond to another point that has failed in the current pandemic - Data Management. The entity should be responsible for previously defining the metrics of morbidity and mortality, systems of data collection, registration, and consolidation, to prevent information cacophony recurrence in countries with different data collection times, metrics, and regional data, among other aspects. Whatever the data, it must be possible to consolidate with sufficient quality to be elements itself in combating the pandemic.

The entity's nature is essentially national, but it should not be exhausted. For example, it must provide for the capacity to reinforce other similar national branches when necessary. Again, there is a need to strengthen international cooperation. Still, for it to be effective, the types of action must be aligned between countries. For example, materials are compatible, procedures are acceptable elsewhere, national laws and rules are not overlapped. 
Another critical point in creating an entity of this nature is to support information management/literacy of the populations/literacy of journalists/literacy of politicians about the pandemic through specific and specialized communication tools.

This set of proposals represents a significant investment. However, no more than millionths of the cost that has been incurred so far. The current century is likely to be the century of pandemics.

\section{Conclusions}

We must start preparing for the next pandemic. The proposal aims to present an organizational alternative for improvements into many points that went wrong in the COVID-19 pandemic: international cooperation, scientific reading, prompt action, transmission mitigation, critical materials supply chains, decision-making processes, preventive action.

Most Western action comprised waiting and acting with hospital facilities until exhaustion and accepting successive pandemic waves as something natural, which is not. COVID-19 was worse enough to repeat without having learned anything.

The countries judged to be most well-prepared for a pandemic in 2018, in many cases performed poorly. Much of the failures were attributable towards political positions and indecision. There is no more room for national approaches.

If politicians are able to commit to these new international mess structures, and an expanded and enhanced role for the World Health Organisation, it will be a demonstration of a willingness to pool sovereignty and recoil from the narrowminded nationalism that has cost so many lives in this pandemic. The world will be a safer place, and humanity will have stepped back from the cliff edge.

\section{Abbreviations}

2PF - Pandemic Preparation Framework; CDC - Centers for Disease Control and Prevention; ECDC European Centre for Disease Prevention and Control; EFFIS - European Forest Fire Information System; FEMA - Federal Emergency Management Agency; HERA - European Health Emergency Preparedness and Response Authority; JIT - Just in Time; pMhab. - per one million inhabitants; PPE - Protective Personal Equipment; UN - United Nations; UNISDR - United Nations Office for Disaster Risk Reduction; WHO - World Health Organization.

\section{Declarations}

Ethics approval and consent to participate: Not applicable.

Consent for publication: Not applicable.

Availability of data and materials: Not applicable.

Competing interests: The authors declare that they have no competing interests. 
Funding: No funding was received for this article.

Author's Contributions: The authors contributed equally for the production of this article. All authors read and approved the final manuscript.

Acknowledgments: The authors acknowledge Diogo Franco of the USP-ICS/UCP scientific secretariat for the support in this article.

\section{References}

1. ASPHER. What is Inequality? Basic Health Inequality Concepts for Understanding the COVID-19 Pandemic [Internet]. 2020. 1-65 p. Available from: https://www.aspher.org/download/515/what_is_inequality.pdf

2. Prajapati N, Łaszewska A, Franco D, Ericson R, Leroy S, Lindert J, et al. What are the COVID-19 Lockdown-induced illnesses and why should European public health systems be investigating their epidemiology, treatment, and prevention? 2020.

3. The Guardian. "Escape the pandemic in paradise": Fiji opens its borders seeking billionaires [Internet]. 2020 [cited 2021 Jan 14]. Available from: https://www.theguardian.com/world/2020/jun/28/escape-thepandemic-in-paradise-fiji-opens-its-borders-seeking-billionaires

4. Worldometer. COVID-19 CORONAVIRUS PANDEMIC [Internet]. 2021 [cited 2021 Mar 10]. Available from: https://www.worldometers.info/coronavirus/

5. OECD. Social economy and the COVID-19 crisis: current and future roles, [Internet]. 2020. Available from: http://www.oecd.org/coronavirus/policy-responses/social-economy-and-the-covid-19-crisis-current-andfuture-roles-f904b89f/

6. The World. These maps show where the world's youngest and oldest people live [Internet]. 2014 [cited 2021 Jan 15]. Available from: https://www.pri.org/stories/2014-09-08/these-maps-show-where-world-syoungest-and-oldest-people-live

7. Scerri M, Grech V. To wear or not to wear? Adherence to face mask use during the COVID-19 and Spanish influenza pandemics. Early Hum Dev. 2020;

8. Melidou A, Pereyaslov D, Hungnes O, Prosenc K, Alm E, Adlhoch C, et al. Virological surveillance of influenza viruses in the WHO European Region in 2019/20 - Impact of the COVID-19 pandemic. Eurosurveillance [Internet]. 2020;25(46):1-10. Available from: http://dx.doi.org/10.2807/15607917.ES.2020.25.46.2001822

9. Czeisler MÉ, Marynak K, Clarke KEN, Salah Z, Shakya I, Thierry JM, et al. Delay or Avoidance of Medical Care Because of COVID-19-Related Concerns - United States, June 2020. MMWR Morb Mortal Wkly Rep. 2020;69(36):1250-7.

10. Sadler D, DeCara JM, Herrmann J, Arnold A, Ghosh AK, Abdel-Qadir H, et al. Perspectives on the COVID-19 pandemic impact on cardio-oncology: results from the COVID-19 International Collaborative Network survey. Cardio-Oncology. 2020;6(1):1-13.

11. Goyal H, Gajendran M, Boregowda U, Perisetti A, Aziz M, Bansal P, et al. Current and future implications of COVID-19 on gastroenterology training and clinical practice. Int J Clin Pract. 2020;74(12):1-10. 
12. Cheng VCC, Lau SKP, Woo PCY, Kwok YY. Severe acute respiratory syndrome coronavirus as an agent of emerging and reemerging infection. Clin Microbiol Rev. 2007;20(4):660-94.

13. McMahonid DE, Peters GA, Iversid LC, Freemanid EE. Global resource shortages during covid-19: Bad news for low-income countries. PLoS Negl Trop Dis [Internet]. 2020;14(7):1-3. Available from: http://dx.doi.org/10.1371/journal.pntd.0008412

14. Valla N. Boosting the Economic Recovery or Closing a Green Deal in Europe? Or Both? Intereconomics. 2020;55(6):350-2.

15. McKinsey \& Company. How prioritizing health could help rebuild economies [Internet]. 2020 [cited 2021 Jan 14]. Available from: https://www.mckinsey.com/industries/healthcare-systems-and-services/ourinsights/how-prioritizing-health-could-help-rebuild-economies\#

16. Eurostat. Unemployment by sex and age - monthly data [Internet]. 2021 [cited 2021 Jan 14]. Available from: https://ec.europa.eu/eurostat/databrowser/view/une_rt_m/default/table?lang=en

17. Mosser PC. Central bank responses to COVID-19. Bus Econ [Internet]. 2020;55(4):191-201. Available from: https://doi.org/10.1057/s11369-020-00189-x

18. Ottersen OP, Engebretsen E. COVID-19 puts the Sustainable Development Goals center stage. Nat Med. 2020;26:1671-2.

19. Melidou A, Pereyaslov D, Hungnes O, Prosenc K, Alm E, Adlhoch C, et al. Virological surveillance of influenza viruses in the WHO European Region in 2019/20 - Impact of the COVID-19 pandemic.

Eurosurveillance. 2020;25(46):1-10.

20. Burki T. Global shortage of personal protective equipment. Lancet Infect Dis [Internet]. 2020;20(7):785-6. Available from: http://dx.doi.org/10.1016/S1473-3099(20)30501-6

21. Park C-Y, Kim K, Roth S, Beck S, Kang JW, Tayag MC, et al. Global Shortage of Personal Protective Equipment amid COVID-19: Supply Chains, Bottlenecks, and Policy Implications. ADB Briefs. 2020;

22. Chen Z, He S, Li F, Yin J, Chen X. Mobile field hospitals, an effective way of dealing with COVID-19 in China: sharing our experience. Biosci Trends. 2020;14(3):212-4.

23. Soutullo C, Díez-Suárez A, Hernández-González C. Challenges during the Covid-19 Pandemic in Spain and Houston. Coping with chaos, moving forward. IACAPAP Bull [Internet]. 2020;(58):18-20. Available from: https://iacapap.org/content/uploads/Bulletin-Issue58.pdf

24. Reuters. France to transfer critical coronavirus patients by train to ease hospital pressure. 2020.

25. The New York Times. Finland, 'Prepper Nation of the Nordics,' Isn't Worried About Masks. 2020.

26. European Comission. European Forest Fire Information System (EFFIS) [Internet]. 2020. Available from: https://effis.jrc.ec.europa.eu/

27. World Health Organization. Global influenza strategy 2019-2030 [Internet]. Geneva; 2019. 34 p. Available from: https://apps.who.int/iris/bitstream/handle/10665/311184/9789241515320-eng.pdf?ua=1

28. Pandemic Influenza Preparedness Framework: progress report 1 January - 30 June 2020. Maintaining surveillance of influenza and monitoring SARS-CoV-2 - adapting Global Influenza surveillance and Response System (GISRS) and sentinel systems during the COVID-19 pandemic: Interim guidance [Internet]. Geneva; 2020. Available from: http://apps.who.int/bookorders. 
29. World Health Organization. Pandemic Influenza Preparedness Framework: progress report, 1 January 30 June 2020. Geneva; 2020.

30. OECD/European Union. How resilient have European health systems been to the COVID-19 crisis? In: Health at a Glance: Europe 2020: State of Health in the EU Cycle. Paris: OECD Publishing; 2020.

31. Gostin LO, Koh HH, Williams M, Hamburg MA, Benjamin G, Foege WH, et al. US withdrawal from WHO is unlawful and threatens global and US health and security. Lancet. 2020;396(10247):293-5.

32. Braithwaite J, Tran Y, Ellis LA, Westbrook J. The 40 health systems, COVID-19 (40HS, C-19) study. Int J Qual Heal Care. 2020;00(00):1-7.

33. Fleming PJ, Spolum MM, Lopez WD, Galea S. The Public Health Funding Paradox: How Funding the Problem and Solution Impedes Public Health Progress. Public Health Rep. 2021;136(1):10-3.

34. WWF. Living Planet Report 2020 - Bending the curve of biodiversity loss. Almond REA, M. G, Petersen T, editors. Gland, Switzerland: WWF; 2020.

35. European Comission. European Health Emergency Preparedness and Response Authority (HERA). 2021.

36. The Telegraph. No government can address the threat of pandemics alone - we must come together. 2021.

37. UN, ISDR. Hyogo framework for action 2005-2015: Building the Resilience of Nations and Communities to Disasters [Internet]. Kobe, Japan; 2005. Available from:

https://www.unisdr.org/2005/wcdr/intergover/official-doc/L-docs/Hyogo-framework-for-actionenglish.pdf

38. UNISDR. Sendai Framework for Disaster Risk Reduction 2015 - 2030 [Internet]. Geneva; 2015. Available from: https://www.preventionweb.net/files/43291_sendaiframeworkfordrren.pdf

39. UN. COVID-19 Impacting Global Security with Heightened Volatility, Increased Threats to United Nations Personnel, Secretary-General Says in New Report. 2020.

40. Gaub F, Boswinkel L. COVID-19: the geopolitical implications of a global pandemic [Internet]. European Parliament's Committee on Foreign Affairs. 2020. Available from: https://www.europarl.europa.eu/RegData/etudes/STUD/2020/603511/EXPO_STU(2020)603511_EN.pdf

41. The Guardian. US accused of "modern piracy" after diversion of masks meant for Europe [Internet]. 2020 [cited 2020 May 5]. Available from: https://www.theguardian.com/world/2020/apr/03/mask-warscoronavirus-outbidding-demand

42. The Guardian. The world needs a patent waiver on Covid vaccines. Why is the UK blocking it? [Internet]. 2021 [cited 2021 Apr 19]. Available from:

https://www.theguardian.com/commentisfree/2021/apr/18/patent-waiver-covid-vaccines-uk-variants? CMP=Share_iOSApp_Other

43. Thebmjopinion. Covid-19 vaccines: a game of power jabs [Internet]. 2021 [cited 2021 Apr 19]. Available from: https://blogs.bmj.com/bmj/2021/04/16/covid-19-vaccines-a-game-of-power-jabs/

44. Herlitz A, Lederman Z, Miller J, Fleurbaey M, Venkatapuram S, Atuire C, et al. Just allocation of COVID-19 vaccines. BMJ Glob Heal. 2021;6(2):e004812.

45. Euractive. Germany, Austria, Spain, Commission to help Portugal deal with third COVID-wave. 2021.

46. WHO. Human infection with avian influenza A (H5N8) - the Russian Federation. 2021. 
47. Pig Progress. ASF Poland: Virus hits farm in the west with 16,000 pigs. 2021.

48. UNISDR. Sendai Framework for Disaster Risk Reduction 2015 - 2030. Geneva; 2015.

49. The Atlantic. The World's Worst Industrial Disaster Is Still Unfolding. 2018.

50. Abbasi K. Covid-19: Politicisation, "corruption," and suppression of science. BMJ. 2020;371:1-2.

51. Jornal Económico. Covid-19. German team starts treating first patients on Monday. 2021.

\section{Figures}

\section{Prevention}

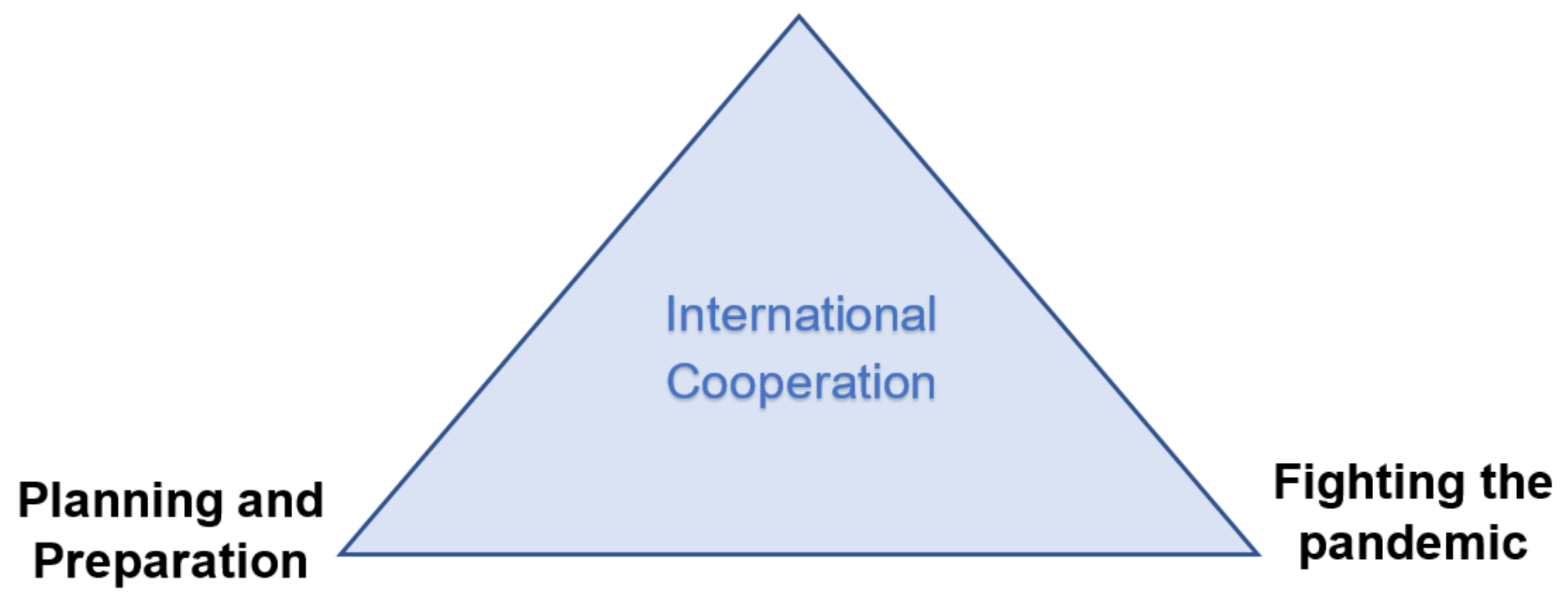

Figure 1

2PF Principles 